\title{
Article \\ Association of Adherence to the Mediterranean Diet with All-Cause Mortality in Subjects with Heart Failure
}

\author{
Chih-Yun Chang ${ }^{1}$, Chia-Lin Lee ${ }^{1,2,3,4}$, Wei-Ju Liu ${ }^{2, *}$ and Jun-Sing Wang ${ }^{1,3,4,5, * \mathbb{C}}$
}

1 Division of Endocrinology and Metabolism, Department of Internal Medicine, Taichung Veterans General Hospital, Taichung 40705, Taiwan; cowmilk38@gmail.com (C.-Y.C.); u502107@yahoo.com.tw (C.-L.L.)

2 Department of Medical Research, Taichung Veterans General Hospital, Taichung 40705, Taiwan

3 Department of Medicine, School of Medicine, National Yang Ming Chiao Tung University, Taipei 11221, Taiwan

4 College of Medicine, National Chung Hsing University, Taichung 40227, Taiwan

5 Rong Hsing Research Center for Translational Medicine, Institute of Biomedical Science, National Chung Hsing University, Taichung 40227, Taiwan

* Correspondence: u103092002@cmu.edu.tw (W.-J.L.); jswang@vghtc.gov.tw (J.-S.W.); Tel.: +886-4-23592525 (W.-J.L. \& J.-S.W.)

check for updates

Citation: Chang, C.-Y.; Lee, C.-L.; Liu, W.-J.; Wang, J.-S. Association of Adherence to the Mediterranean Diet with All-Cause Mortality in Subjects with Heart Failure. Nutrients 2022, 14, 842. https://doi.org/10.3390/ nu14040842

Academic Editors: Bradley

S. Ferguson and Antoni Pons

Received: 29 December 2021

Accepted: 15 February 2022

Published: 17 February 2022

Publisher's Note: MDPI stays neutral with regard to jurisdictional claims in published maps and institutional affiliations.

Copyright: (C) 2022 by the authors. Licensee MDPI, Basel, Switzerland. This article is an open access article distributed under the terms and conditions of the Creative Commons Attribution (CC BY) license (https:// creativecommons.org/licenses/by/ $4.0 /)$.

\begin{abstract}
We investigated the associations of adherence to the Mediterranean diet with all-cause and cardiovascular mortality in patients with heart failure. We analyzed the National Health and Nutrition Examination Survey (NHANES) participants from 1999 to 2010, with their vital status confirmed through to the end of 2011. The alternate Mediterranean Diet Index (aMED) was used to assess study participants' adherence to the Mediterranean diet according to information on dietary questionnaires. We conducted weighted Cox proportional hazards regression models to determine the associations of adherence to the Mediterranean diet (aMED $\geq$ median vs. $<$ median) with all-cause and cardiovascular mortality in participants with a history of heart failure. A total of 832 participants were analyzed, and the median aMED was 3. After a median follow-up of 4.7 years, 319 participants had died. aMED $\geq 3$ (vs. <3) was not associated with a lower risk of all-cause (adjusted HR 0.797, 95\% CI 0.599-1.059, $p=0.116$ ) and cardiovascular (adjusted HR 0.911, 95\% CI 0.539-1.538, $p=0.724$ ) mortality. The findings were consistent across several subgroup populations. Among the components of aMED, a lower intake of red/processed meat was associated with a higher risk of mortality (adjusted HR 1.406, 95\% CI 1.011-1.955, $p=0.043$ ). We concluded that adherence to the Mediterranean diet was not associated with a lower risk of all-cause and cardiovascular mortality in participants with a history of heart failure. The higher risk of mortality associated with a lower intake of red/processed meat deserves further investigation.
\end{abstract}

Keywords: Mediterranean diet; aMED; NHANES; heart failure; mortality

\section{Introduction}

Despite a modest decrease in the incidence of heart failure in recent decades [1-3], the rate of all-cause mortality remains high [3-5]. In a recent large cohort study [6], the 5-year survival rate was less than $50 \%$ in patients with newly diagnosed heart failure. Among the patients who were admitted to hospital at the time of diagnosis [6], the 5-year survival rate was less than $40 \%$. This disease has been reported to be as "malignant" as some kinds of cancers [4].

In addition to pharmacologic treatment, lifestyle modification and healthy dietary patterns (such as the Mediterranean diet) have been recommended to reduce cardiovascular risk [7]. In people with obesity, adopting the Mediterranean diet was effective in improving lipid values and glycemic control, as well as achieving weight reduction [8]. Moreover, adherence to the Mediterranean diet, assessed using the alternate Mediterranean Diet Index 
(aMED) $[9,10]$, has been associated with a lower risk of all-cause mortality in the general population [11-13].

Malnutrition is an important issue for patients with heart failure [14,15], and there have been some reports on dietary recommendations for these patients [16,17]. Nevertheless, the effect of adopting the Mediterranean diet on risk of all-cause mortality in patients with heart failure [18] is not yet clear. We conducted this study to investigate the association of adherence to the Mediterranean diet with risk of all-cause and cardiovascular mortality in patients with heart failure.

\section{Materials and Methods}

We analyzed data from NHANES participants in this study. The NHANES was conducted by the National Center for Health Statistics to assess the health and nutritional status of the general population. Relevant dietary information was collected using $24 \mathrm{~h} \mathrm{di-}$ etary recall questionnaires (https:/ / wwwn.cdc.gov/nchs/nhanes/Search/DataPage.aspx? Component=Dietary\&CycleBegin Year=2005, accessed on 26 January 2022). We determined dietary concordance with the Mediterranean diet using the aMED [9,10], which has been applied to the NHANES population. Information on all-cause and cardiovascular mortality was obtained by linking to the National Death Index up to the end of 2011. This study was conducted in accordance with the Declaration of Helsinki. All of the NHANES participants provided informed consent. We had our study protocol approved by the Institutional Review Board of Taichung Veterans General Hospital, Taichung, Taiwan (approval number: CE18312A) prior to conduction of the study.

\subsection{Study Population}

Figure 1 shows the selection process for the study population. From 1999 to 2010, there were 62,160 participants in the NHANES. We excluded those who were aged $\leq 18$ years, had missing data on questionnaires for nutrient intake and renal function, or had unknown or no history of heart failure. Finally, the study population consisted of 832 participants who reported a history of heart failure.

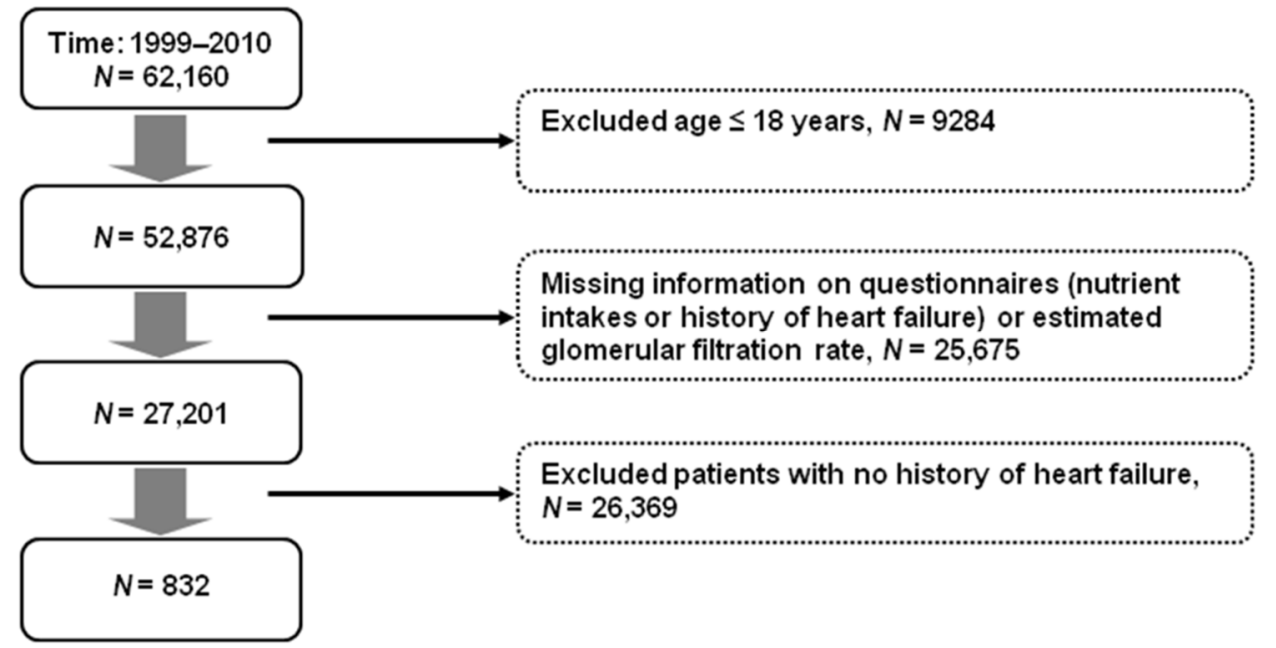

Figure 1. Selection process for the study population.

\subsection{Procedure and Outcome}

We used aMED $[9,10]$ to assess the study population's dietary concordance with the Mediterranean diet. The study participants' intakes of alcohol, red and processed meat, seafood, whole grains, legumes, nuts, fruits, vegetables (except potatoes), and ratio of monounsaturated to saturated fat were determined according to the information obtained from the $24 \mathrm{~h}$ dietary recall questionnaires. One point was assigned to study participants who had an intake of the aforementioned components (except for alcohol 
and red/processed meat) higher than the median for the population. For alcohol and red/processed meat, one point was assigned to those who had moderate alcohol consumption (10-25 g/day for men and 5-15 g/day for women) or a meat intake that was less than the median for the population. Those who did not have an intake of these components meeting the aforementioned criteria received 0 points. The maximum score was 9. The higher the aMED, the better the concordance with the Mediterranean diet. The Chronic Kidney Disease Epidemiology Collaboration equation [19] was used to determine the estimated glomerular filtration rate (eGFR). The primary outcome of this study was all-cause mortality (https://www.cdc.gov/nchs/data/nhsr/nhsr143-508.pdf, accessed on 26 January 2022). As the ankle-brachial index (ABI) has been associated with risk of mortality in patients with heart failure $[20,21]$, the associations of aMED and ABI with all-cause and cardiovascular (including death due to heart diseases or cerebrovascular diseases) mortality were examined as well.

\subsection{Statistical Analysis}

We conducted the statistical analyses using the Statistical Analysis System survey procedures (SAS version 9.4, 2013, Cary, NC, USA) according to the analytic guidelines (https: / / wwwn.cdc.gov/nchs/nhanes/analyticguidelines.aspx, accessed on 26 January 2022). The study population was divided into two groups according to their aMED ( $\geq$ median vs. $<$ median) [22-24]. Between-group differences in categorical and continuous variables were tested using the Chi-square test and the independent sample $t$-test, respectively. We used weighted Cox proportional hazards regression models to determine the hazard ratios (HR) and $95 \%$ CI for the associations of adherence to the Mediterranean diet (aMED $\geq$ median vs. $<$ median) with all-cause and cardiovascular mortality, with adjustments for age, sex, race, body mass index, smoking, systolic blood pressure, diabetes, eGFR, and daily energy intake. We conducted subgroup analyses in study participants with different body mass indexes ( $\geq 30$ vs. $<30 \mathrm{~kg} / \mathrm{m}^{2}$ ), daily energy intake ( $\geq 25 \mathrm{vs}$. $<25 \mathrm{kcal} / \mathrm{kg} /$ day), glucose regulation status (diabetes vs. no diabetes), and renal function (eGFR $\geq 60$ vs. $<60 \mathrm{~mL} / \mathrm{min} / 1.73 \mathrm{~m}^{2}$ ). The associations of the 9 components of aMED with all-cause and cardiovascular mortality were also examined. Statistical significance was confirmed with a two-sided $p$ value $<0.05$.

\section{Results}

\subsection{Characteristics of the Population}

Table 1 shows the baseline characteristics of the study participants according to aMED ( $\geq 3$ vs. <3). Participants with an aMED $\geq 3$ were older, and had a lower body mass index, a lower rate of smoking, and a better lipid profile (lower total cholesterol and triglyceride, and higher high-density lipoprotein cholesterol) compared to those who had an aMED $<3$. There were also significant between-group differences in systolic and diastolic blood pressure, fasting plasma glucose, glycated hemoglobin (HbA1c), eGFR, and daily calorie intake. However, the differences were only modest.

Table 1. Characteristics of study participants according to aMED.

\begin{tabular}{cccc}
\hline & \multicolumn{2}{c}{ aMED } & \\
\cline { 2 - 3 } Variables & $<3$ & $\geq \mathbf{3}$ & $\boldsymbol{p}$ \\
\hline Number of participants & 468 & 364 & \\
Age, years & $64.0(62.3-65.6)$ & $67.8(65.8-69.8)$ & $<0.001$ \\
Male, $n(\%)$ & $275(54.5)$ & $204(54.6)$ & 0.969 \\
Body mass index, $\mathrm{kg} / \mathrm{m}^{2}$ & $31.2(30.4-32.0)$ & $30.7(29.6-31.7)$ & $<0.001$ \\
Systolic blood pressure, $\mathrm{mm} \mathrm{Hg}$ & $130.5(127.9-133.1)$ & $131.8(129.0-134.7)$ & $<0.001$ \\
Diastolic blood pressure, $\mathrm{mm} \mathrm{Hg}$ & $67.7(65.5-70.0)$ & $66.7(64.6-68.8)$ & $<0.001$ \\
\hline
\end{tabular}


Table 1. Cont.

\begin{tabular}{cccc}
\hline & \multicolumn{2}{c}{ aMED } & \\
\cline { 2 - 4 } Variables & $<3$ & $\geq \mathbf{3}$ \\
\hline Hypertension, $n(\%)$ & $340(67.5)$ & $273(71.9)$ & 0.211 \\
Smoking, $n(\%)$ & $320(68.0)$ & $204(55.8)$ & 0.005 \\
Total cholesterol, mg/dL & $190.7(184.9-196.6)$ & $187.0(182.1-192.0)$ & $<0.001$ \\
HDL cholesterol, mg/dL & $47.6(45.8-49.4)$ & $50.9(48.7-53.1)$ & $<0.001$ \\
Triglycerides, mg/dL & $179.0(163.9-194.0)$ & $158.8(146.3-171.4)$ & $<0.001$ \\
Fasting plasma glucose, mg/dL & $114.9(108.8-121.1)$ & $118.6(112.1-125.0)$ & $<0.001$ \\
HbA1c, \% & $6.03(5.89-6.17)$ & $6.17(6.03-6.31)$ & $<0.001$ \\
eGFR, mL/min/1.73 m 2 & $71.1(67.7-74.5)$ & $69.7(66.1-73.3)$ & $<0.001$ \\
Daily calories, kcal/day & $1748(1636-1860)$ & $1802(1691-1913)$ & $<0.001$ \\
\% from carbohydrate & $48.9(47.9-49.8)$ & $52.3(51.2-53.5)$ & \\
$\%$ from fat & $35.0(34.1-36.0)$ & $32.1(31.1-33.2)$ & \\
\% from protein & $16.1(15.5-16.8)$ & $15.6(14.9-16.3)$ & \\
With ankle-brachial index data, $n$ & 213 & 63 & 0.792 \\
Ankle-brachial index $\leq 0.9, n(\%)$ & $38(19.5)$ & $25(18.2)$ & \\
\hline
\end{tabular}

Data are presented as mean (95\% CI) or $n(\%)$. aMED, alternative Mediterranean Diet Index. eGFR, estimated glomerular filtration rate. $\mathrm{HbA1c}$, glycated hemoglobin. HDL, high-density lipoprotein.

\subsection{Outcome}

3.2.1. Association with aMED ( $\geq 3$ vs. $<3)$ and ABI ( $\leq 0.9$ vs. $>0.9)$

After a median follow-up of 4.7 years, a total of 319 participants had died (69.5 per 1000 person-years). Table 2 shows the associations of aMED ( $\geq 3$ vs. $<3)$ and ABI $(\leq 0.9$ vs. $>0.9)$ with all-cause and cardiovascular mortality. Overall, a higher aMED was associated with a non-significantly lower risk of all-cause (adjusted HR 0.797, 95\% CI 0.599-1.059, $p=0.116$ ) and cardiovascular (adjusted HR 0.911, 95\% CI 0.539-1.538, $p=0.724$ ) mortality. In contrast, an $\mathrm{ABI} \leq 0.9$ (vs. $>0.9$ ) was associated with a significantly higher risk of all-cause (adjusted HR 2.206, 95\% CI 1.412-3.447, $p<0.001$ ) and cardiovascular (adjusted HR 2.027, 95\% CI 1.008-4.075, $p=0.048)$ mortality. The associations of aMED ( $\geq 3$ vs. $<3$ ) with all-cause and cardiovascular mortality were similar across subgroups of age, sex, body mass index, calorie intake, diabetes, and renal function (eGFR) (Table 3).

Table 2. Associations of aMED and ankle-brachial index with all-cause and cardiovascular mortality.

\begin{tabular}{ccc}
\hline & Adjusted HR (95\% CI) ${ }^{\dagger}$ & $p$ \\
\hline All-cause mortlity & & \\
aMED $(\geq 3$ vs. $<3)$ & $0.797(0.599-1.059)$ & 0.116 \\
Ankle-brachial index $(\leq 0.9$ vs. $>0.9)$ & $2.206(1.412-3.447)$ & $<0.001$ \\
Cardiovascular mortality mortality & & 0.724 \\
aMED $(\geq 3$ vs. $<3)$ & $0.911(0.539-1.538)$ & 0.048
\end{tabular}

aMED, alternative Mediterranean Diet Index. ${ }^{\dagger}$ Adjusted for age, sex, race, body mass index, smoking, systolic blood pressure, diabetes, estimated glomerular filtration rate, and daily energy intake.

\subsubsection{Association with Individual Components of aMED}

Table 4 shows the associations of aMED components with all-cause and cardiovascular mortality. There were no significant associations between the components of aMED with the risk of mortality, except for alcohol and red/processed meat. Moderate alcohol consumption (score $=1$ ) was associated with a modest reduction in all-cause (HR 0.522, 95\% CI 0.243-1.123, $p=0.095$ ) and cardiovascular (HR 0.324, 95\% CI 0.132-0.794, $p=0.014$ ) mortality. In contrast, a lower intake of red/processed meat (score $=1$ ) was associated with a significantly higher risk of all-cause mortality (HR 1.406, 95\% CI 1.011-1.955, $p=0.043$ ). 
Table 3. Association of aMED ( $\geq 3$ vs. $<3$ ) with all-cause and cardiovascular mortality in subgroups.

\begin{tabular}{ccccc}
\hline & $\begin{array}{c}\text { All-Cause Mortality } \\
\text { Adjusted HR (95\% CI) }\end{array}$ & $\boldsymbol{p}$ & $\begin{array}{c}\text { Cardiovascular Mortality } \\
{ }^{+}\end{array}$ & Adjusted HR (95\% CI) $^{\dagger}$ \\
\hline Age $<$ 65 years & $0.682(0.239-1.943)$ & 0.470 & $0.529(0.101-2.765)$ & 0.447 \\
Age $\geq$ 65 years & $0.983(0.733-1.319)$ & 0.907 & $1.121(0.651-1.929)$ & 0.677 \\
Male & $0.720(0.480-1.081)$ & 0.112 & $1.035(0.508-2.107)$ & 0.924 \\
Female & $0.899(0.592-1.366)$ & 0.614 & $0.794(0.432-1.458)$ & 0.452 \\
Body mass index $<30 \mathrm{~kg} / \mathrm{m}^{2}$ & $0.740(0.523-1.047)$ & 0.088 & $0.684(0.385-1.217)$ & 0.194 \\
Body mass index $\geq 30 \mathrm{~kg} / \mathrm{m}^{2}$ & $0.846(0.502-1.426)$ & 0.527 & $1.379(0.621-3.061)$ & 0.425 \\
Calorie intake $<25 \mathrm{kcal} / \mathrm{kg} /$ day & $0.784(0.556-1.106)$ & 0.163 & $0.886(0.481-1.633)$ & 0.695 \\
Calorie intake $\geq 25 \mathrm{kcal} / \mathrm{kg} /$ day & $0.909(0.552-1.496)$ & 0.704 & $1.176(0.506-2.734)$ & 0.703 \\
No diabetes & $0.910(0.663-1.249)$ & 0.557 & $0.733(0.450-1.194)$ & 0.209 \\
Diabetes & $0.745(0.418-1.029)$ & 0.314 & $1.268(0.494-3.253)$ & 0.618 \\
eGFR $\geq 60 \mathrm{~mL} / \mathrm{min} / 1.73 \mathrm{~m}^{2}$ & $0.685(0.455-1.029)$ & 0.068 & $0.935(0.492-1.778)$ & 0.837 \\
eGFR $<60 \mathrm{~mL} / \mathrm{min} / 1.73 \mathrm{~m}^{2}$ & $0.780(0.524-1.159)$ & 0.216 & $0.802(0.443-1.452)$ & 0.462 \\
\hline
\end{tabular}

aMED, alternative Mediterranean Diet Index. eGFR, estimated glomerular filtration rate. ${ }^{\dagger}$ Adjusted for age, sex, race, body mass index, smoking, systolic blood pressure, diabetes, eGFR, and daily energy intake.

Table 4. Associations of individual components of the aMED with all-cause and cardiovascular mortality.

\begin{tabular}{|c|c|c|c|c|}
\hline & \multicolumn{2}{|c|}{ All-Cause Mortality } & \multicolumn{2}{|c|}{ Cardiovascular Mortality } \\
\hline & Adjusted HR (95\% CI) ${ }^{\dagger}$ & $p$ & Adjusted HR (95\% CI) ${ }^{\dagger}$ & $p$ \\
\hline Alcohol score $=0$ & 1 (reference) & & 1 (reference) & \\
\hline Alcohol score $=1$ & $0.522(0.243-1.123)$ & 0.095 & $0.324(0.132-0.794)$ & 0.014 \\
\hline Red $/$ processed meat score $=0$ & 1 (reference) & & 1 (reference) & \\
\hline Red $/$ processed meat score $=1$ & $1.406(1.011-1.955)$ & 0.043 & $1.125(0.656-1.929)$ & 0.665 \\
\hline Sea food score $=0$ & 1 (reference) & & 1 (reference) & \\
\hline Sea food score $=1$ & $0.960(0.621-1.484)$ & 0.854 & $0.776(0.392-1.537)$ & 0.463 \\
\hline Whole grains score $=0$ & 1 (reference) & & 1 (reference) & \\
\hline Whole grains score $=1$ & $0.953(0.713-1.274)$ & 0.743 & $1.054(0.625-1.778)$ & 0.842 \\
\hline Legumes score $=0$ & 1 (reference) & & 1 (reference) & \\
\hline Legumes score $=1$ & $0.764(0.572-1.020)$ & 0.068 & $0.793(0.442-1.423)$ & 0.432 \\
\hline Nuts score $=0$ & 1 (reference) & & 1 (reference) & \\
\hline Nuts score $=1$ & $0.940(0.699-1.265)$ & 0.682 & $1.053(0.642-1.728)$ & 0.836 \\
\hline Fruits score $=0$ & 1 (reference) & & 1 (reference) & \\
\hline Fruits score $=1$ & $0.884(0.638-1.223)$ & 0.451 & $1.060(0.626-1.794)$ & 0.826 \\
\hline Vegetables score $=0$ & 1 (reference) & & 1 (reference) & \\
\hline Vegetables score $=1$ & $0.966(0.714-1.306)$ & 0.820 & $1.084(0.711-1.653)$ & 0.706 \\
\hline MUFA /SFA score $=0$ & 1 (reference) & & 1 (reference) & \\
\hline MUFA $/$ SFA score $=1$ & $0.979(0.739-1.296)$ & 0.879 & $0.804(0.512-1.264)$ & 0.341 \\
\hline
\end{tabular}

aMED, alternative Mediterranean Diet Index. MUFA, monounsaturated fat. SFA, saturated fat. ${ }^{\dagger}$ Adjusted for age, sex, race, body mass index, smoking, systolic blood pressure, diabetes, estimated glomerular filtration rate, and daily energy intake.

3.2.3. Association with aMED Score for Red/Processed Meat (Lower Intake vs. Higher Intake) in Subgroups

The higher risk of all-cause mortality associated with a lower intake of red/processed meat (score $=1$ ) was examined in subgroups. The association was noted in subgroups of age $\geq 65$ years, female, body mass index $\geq 30 \mathrm{~kg} / \mathrm{m}^{2}$, diabetes, and eGFR $<60 \mathrm{~mL} / \mathrm{min} / 1.73 \mathrm{~m}^{2}$ (Table 5). 
Table 5. Associations of aMED score for red/processed meat (1 vs. 0$)$ with all-cause mortality in subgroups.

\begin{tabular}{ccc}
\hline & Adjusted HR (95\% CI) ${ }^{\dagger}$ & $p$ \\
\hline Overall & $1.406(1.011-1.955)$ & 0.043 \\
Age $<65$ years & $0.944(0.363-2.452)$ & 0.905 \\
Age $\geq 65$ years & $1.524(1.092-2.127)$ & 0.014 \\
Male & $1.207(0.712-2.046)$ & 0.481 \\
Female & $1.665(1.106-2.508)$ & 0.015 \\
Body mass index $<30 \mathrm{~kg} / \mathrm{m}^{2}$ & $1.111(0.796-1.551)$ & 0.530 \\
Body mass index $\geq 30 \mathrm{~kg} / \mathrm{m}^{2}$ & $1.795(1.001-3.219)$ & 0.049 \\
Calorie intake $<25 \mathrm{kcal} / \mathrm{kg} /$ day & $1.473(0.980-2.215)$ & 0.063 \\
Calorie intake $\geq 25 \mathrm{kcal} / \mathrm{kg} /$ day & $1.559(0.849-2.860)$ & 0.150 \\
No diabetes & $0.979(0.684-1.403)$ & 0.909 \\
Diabetes & $2.318(1.404-3.828)$ & 0.001 \\
eGFR $\geq 60 \mathrm{~mL} / \mathrm{min} / 1.73 \mathrm{~m}^{2}$ & $0.949(0.542-1.660)$ & 0.852 \\
$\mathrm{eGFR}<60 \mathrm{~mL} / \mathrm{min} / 1.73 \mathrm{~m}^{2}$ & $1.903(1.298-2.791)$ & 0.001 \\
\hline
\end{tabular}

aMED, alternative Mediterranean Diet Index. eGFR, estimated glomerular filtration rate. Score 1 = intake of red/processed meat less than the median of the study population. ${ }^{+}$Adjusted for age, sex, race, body mass index, smoking, systolic blood pressure, diabetes, eGFR, and daily energy intake.

\section{Discussion}

In this study using data from the NHANES, we investigated the association of adherence to the Mediterranean diet with all-cause and cardiovascular mortality in participants with a history of heart failure. We found that aMED $\geq 3$ (vs. <3) was not associated with a lower risk of all-cause (adjusted HR 0.797, 95\% CI 0.599-1.059, $p=0.116)$ and cardiovascular (adjusted HR 0.911, 95\% CI 0.539-1.538, $p=0.724$ ) mortality (Table 2), and the findings were consistent across various subgroups (Table 3 ). In line with previous reports [20,21,25], a low $\mathrm{ABI}(\leq 0.9$ vs. $>0.9)$ was associated with a significantly higher risk of all-cause (HR 2.206, $95 \%$ CI 1.412-3.447, $p<0.001$ ) and cardiovascular (HR 2.027, 95\% CI 1.008-4.075, $p=0.048$ ) mortality. Regarding the individual components of aMED, a lower intake of red/processed meat was associated with a higher risk of all-cause mortality (adjusted HR 1.406, 95\% CI $1.011-1.955, p=0.043$, Table 4). Our findings showed that a dietary pattern concordance with the Mediterranean diet might not be associated with a lower risk of all-cause mortality in patients with heart failure.

A dietary pattern concordant with the Mediterranean diet in the general population has been associated with a lower risk of incident cardiovascular diseases [26-28] and allcause mortality [11-13]. In a well-conducted meta-analysis [29], a Mediterranean dietary pattern was associated with lower risks of cardiovascular disease incidence and mortality. Nevertheless, the associations with incident heart failure were inconsistent [26,30-32]. Furthermore, the effects of adherence to the Mediterranean diet on secondary prevention [33] and all-cause mortality risk $[18,34]$ are not yet clear in patients with heart failure. In a recent study conducted in 991 patients who had an episode of acute heart failure [35], adherence to the Mediterranean diet was not associated with a significantly lower risk of all-cause mortality (HR $0.94,95 \%$ CI $0.80-1.13, p=0.50$ ) during a mean follow-up period of 2.1 years. Our findings are consistent with previous studies [18,34,35], while these results could not support the recommendation of a Mediterranean dietary pattern to reduce risk of all-cause mortality in patients with heart failure.

We examined the associations of individual components of the aMED with all-cause and cardiovascular mortality (Table 4 ). Moderate alcohol consumption (score $=1$ ) was associated with a modest reduction in all-cause (HR 0.522, 95\% CI 0.243-1.123, $p=0.095$ ) and cardiovascular (HR 0.324, 95\% CI 0.132-0.794, $p=0.014$ ) mortality. The findings are consistent with previous studies [36-38]. Surprisingly, a lower intake of red/processed meat (score 1 vs. 0 ) was associated with a higher risk of all-cause mortality (HR 1.406, 95\% CI 1.011-1.955, $p=0.043)$. Red/processed meat consumption had been associated with incident cardiovascular diseases and all-cause mortality in the general population [39-41], 
but the association was not significant in the aforementioned meta-analysis [29]. Intake of processed meat (other than red meat) had also been associated with risk of heart failure [42]. However, the association between red/processed meat intake and all-cause mortality is not yet clear in patients with heart failure. The effects of processed and unprocessed red meat on risk of mortality might be different $[43,44]$. Moreover, patients with heart failure might be predisposed to malnutrition [14,15], and nutritional therapy has become an important issue in treating these patients. Daily protein intake of more than $1.1 \mathrm{~g} / \mathrm{kg}$ is recommended for patients with heart failure to prevent catabolism [16,17]. In a recent randomized controlled study conducted in 76 obese patients with heart failure and diabetes [45], an energyrestricted high-protein diet (30\% protein, $40 \%$ carbohydrate, and 30\% fat) for 3 months resulted in better control of cardiometabolic risk factors than an energy-restricted standardprotein diet (15\% protein, 55\% carbohydrate, and 30\% fat). In our study participants whose intake of red/processed meat was lower, the percentages of daily calories from protein, carbohydrate, and fat were $14.7 \%, 53.2 \%$, and $32.2 \%$, respectively. The respective rates were $17.1 \%, 47.5 \%$, and $35.4 \%$ in those with a higher intake of red/processed meat. An increase in carbohydrate intake may be associated with a higher risk of mortality [46]. We speculate that limited red meat intake in patients with heart failure might lead to inadequate protein intake, and possibly an increase in carbohydrate consumption, both of which could be associated with unfavorable outcomes in susceptible populations (e.g., patients with heart failure, the elderly, etc.) [47-49]. The trade-off between a decrease in protein and an increase in carbohydrate might have even more impacts on participants with diabetes, obesity, or chronic kidney disease [46,50], while a discrepancy between men and women regarding the outcomes cannot be excluded [51]. Whether replacement of animal protein with plant protein may improve survival [52] in patients with heart failure merits further investigation.

\section{Limitations}

Our study has some limitations. First, some measures related to heart failure were not available for analyses. Both left ventricular ejection fraction and serum N-terminal pro-brain natriuretic peptide have been associated with heart failure outcomes. Information about medical treatment for heart failure was lacking. These factors were not adjusted for in our analyses. Second, the dietary information was collected through questionnaires. Although the interviewers in the NHANES were trained to minimize data collection bias, there could have been some discrepancies between the participants' dietary habits and the collected information, which may have confounded our results. Third, dietary concordance with the Mediterranean diet was low in our study population (median aMED =3). Moreover, the number of study participants was relatively small. This might partly explain the null effect of aMED on the mortality risk in our results. Nevertheless, a higher concordance with the Mediterranean diet in a prospective study [35] did not influence long-term mortality in patients who experienced an episode of acute heart failure.

\section{Conclusions}

Adherence to the Mediterranean diet was not associated with risk of all-cause mortality in NHANES participants with a history of heart failure. The association of a higher risk of mortality with a lower intake of red/processed meat in the study population deserves further investigation.

Author Contributions: Conceptualization, C.-Y.C. and J.-S.W.; methodology, C.-Y.C., C.-L.L. and J.-S.W.; software, C.-L.L. and W.-J.L.; formal analysis, C.-L.L. and W.-J.L.; data curation, C.-L.L., W.-J.L. and J.-S.W.; writing-original draft preparation, C.-Y.C. and J.-S.W.; writing-review and editing, C.-L.L. and W.-J.L.; funding acquisition, C.-L.L. and J.-S.W. All authors have read and agreed to the published version of the manuscript.

Funding: This work was supported by Taichung Veterans General Hospital, Taichung, Taiwan [grant numbers TCVGH-1083505C, 2019; TCVGH-1093504C, 2020; TCVGH-1103502C, TCVGH-1103504C, and TCVGH-1107305D, 2021]. 
Institutional Review Board Statement: We conducted this study in accordance with the Declaration of Helsinki. Our protocol was approved by the Institutional Review Board of Taichung Veterans General Hospital (CE18312A; date of approval: 29 September 2020).

Informed Consent Statement: All NHANES participants provided informed consent.

Data Availability Statement: The datasets generated and/or analyzed during the current study are available in the National Center for Health Statistics, Centers for Disease Control and Prevention (https://wwwn.cdc.gov/nchs/nhanes/Search/DataPage.aspx?Component=Dietary\&CycleBeginYear= 2005, accessed on 26 January 2022).

Acknowledgments: We would like to thank the NHANES participants and the staff at the National Center for Health Statistics for collecting the data and making it publicly available.

Conflicts of Interest: There is no conflict of interest. The funders had no role in the design of the study; in the collection, analyses, or interpretation of data; in the writing of the manuscript, or in the decision to publish the results.

\section{References}

1. Levy, D.; Kenchaiah, S.; Larson, M.G.; Benjamin, E.J.; Kupka, M.J.; Ho, K.K.; Murabito, J.M.; Vasan, R.S. Long-term trends in the incidence of and survival with heart failure. N. Engl. J. Med. 2002, 347, 1397-1402. [CrossRef] [PubMed]

2. Conrad, N.; Judge, A.; Tran, J.; Mohseni, H.; Hedgecott, D.; Crespillo, A.P.; Allison, M.; Hemingway, H.; Cleland, J.G.; McMurray, J.J.V.; et al. Temporal trends and patterns in heart failure incidence: A population-based study of 4 million individuals. Lancet 2018, 391, 572-580. [CrossRef]

3. McAllister, D.A.; Read, S.H.; Kerssens, J.; Livingstone, S.; McGurnaghan, S.; Jhund, P.; Petrie, J.; Sattar, N.; Fischbacher, C.; Kristensen, S.L.; et al. Incidence of Hospitalization for Heart Failure and Case-Fatality among 3.25 Million People with and without Diabetes Mellitus. Circulation 2018, 138, 2774-2786. [CrossRef] [PubMed]

4. Mamas, M.A.; Sperrin, M.; Watson, M.C.; Coutts, A.; Wilde, K.; Burton, C.; Kadam, U.T.; Kwok, C.S.; Clark, A.B.; Murchie, P.; et al. Do patients have worse outcomes in heart failure than in cancer? A primary care-based cohort study with 10-year follow-up in Scotland. Eur. J. Heart Fail. 2017, 19, 1095-1104. [CrossRef] [PubMed]

5. Wang, T.D.; Huang, S.T.; Wang, C.Y.; Lin, F.J.; Chen, H.M.; Hsiao, F.Y. Nationwide trends in incidence, healthcare utilization, and mortality in hospitalized heart failure patients in Taiwan. ESC Heart Fail. 2020, 7, 3653-3666. [CrossRef]

6. Taylor, C.J.; Ordóñez-Mena, J.M.; Roalfe, A.K.; Lay-Flurrie, S.; Jones, N.R.; Marshall, T.; Hobbs, F.D.R. Trends in survival after a diagnosis of heart failure in the United Kingdom 2000-2017: Population based cohort study. BMJ 2019, 364, 1223. [CrossRef]

7. Barone Gibbs, B.; Hivert, M.F.; Jerome, G.J.; Kraus, W.E.; Rosenkranz, S.K.; Schorr, E.N.; Spartano, N.L.; Lobelo, F. Physical Activity as a Critical Component of First-Line Treatment for Elevated Blood Pressure or Cholesterol: Who, What, and How?: A Scientific Statement From the American Heart Association. Hypertension 2021, 78, e26-e37. [CrossRef]

8. Shai, I.; Schwarzfuchs, D.; Henkin, Y.; Shahar, D.R.; Witkow, S.; Greenberg, I.; Golan, R.; Fraser, D.; Bolotin, A.; Vardi, H.; et al. Weight loss with a low-carbohydrate, Mediterranean, or low-fat diet. N. Engl. J. Med. 2008, 359, 229-241. [CrossRef]

9. Fung, T.T.; McCullough, M.L.; Newby, P.K.; Manson, J.E.; Meigs, J.B.; Rifai, N.; Willett, W.C.; Hu, F.B. Diet-quality scores and plasma concentrations of markers of inflammation and endothelial dysfunction. Am. J. Clin. Nutr. 2005, 82, 163-173. [CrossRef]

10. Ha, K.; Kim, K.; Sakaki, J.R.; Chun, O.K. Relative Validity of Dietary Total Antioxidant Capacity for Predicting All-Cause Mortality in Comparison to Diet Quality Indexes in US Adults. Nutrients 2020, 12, 1210. [CrossRef]

11. Trichopoulou, A.; Costacou, T.; Bamia, C.; Trichopoulos, D. Adherence to a Mediterranean diet and survival in a Greek population. N. Engl. J. Med. 2003, 348, 2599-2608. [CrossRef] [PubMed]

12. Neelakantan, N.; Koh, W.P.; Yuan, J.M.; van Dam, R.M. Diet-Quality Indexes Are Associated with a Lower Risk of Cardiovascular, Respiratory, and All-Cause Mortality among Chinese Adults. J. Nutr. 2018, 148, 1323-1332. [CrossRef]

13. Hu, E.A.; Steffen, L.M.; Coresh, J.; Appel, L.J.; Rebholz, C.M. Adherence to the Healthy Eating Index-2015 and Other Dietary Patterns May Reduce Risk of Cardiovascular Disease, Cardiovascular Mortality, and All-Cause Mortality. J. Nutr. 2020, 150, 312-321. [CrossRef] [PubMed]

14. Carbone, S.; Lavie, C.J.; Arena, R. Obesity and Heart Failure: Focus on the Obesity Paradox. Mayo Clin. Proc. 2017, 92, 266-279. [CrossRef] [PubMed]

15. Billingsley, H.E.; Hummel, S.L.; Carbone, S. The role of diet and nutrition in heart failure: A state-of-the-art narrative review. Prog. Cardiovasc. Dis. 2020, 63, 538-551. [CrossRef] [PubMed]

16. Kuehneman, T.; Gregory, M.; de Waal, D.; Davidson, P.; Frickel, R.; King, C.; Gradwell, E.; Handu, D. Academy of Nutrition and Dietetics Evidence-Based Practice Guideline for the Management of Heart Failure in Adults. J. Acad. Nutr. Diet 2018, 118, 2331-2345. [CrossRef]

17. Vest, A.R.; Chan, M.; Deswal, A.; Givertz, M.M.; Lekavich, C.; Lennie, T.; Litwin, S.E.; Parsly, L.; Rodgers, J.E.; Rich, M.W.; et al. Nutrition, Obesity, and Cachexia in Patients With Heart Failure: A Consensus Statement from the Heart Failure Society of America Scientific Statements Committee. J. Card. Fail. 2019, 25, 380-400. [CrossRef] 
18. Levitan, E.B.; Lewis, C.E.; Tinker, L.F.; Eaton, C.B.; Ahmed, A.; Manson, J.E.; Snetselaar, L.G.; Martin, L.W.; Trevisan, M.; Howard, B.V.; et al. Mediterranean and DASH diet scores and mortality in women with heart failure: The Women's Health Initiative. Circ. Heart Fail. 2013, 6, 1116-1123. [CrossRef]

19. Levey, A.S.; Stevens, L.A.; Schmid, C.H.; Zhang, Y.L.; Castro, A.F., 3rd; Feldman, H.I.; Kusek, J.W.; Eggers, P.; Van Lente, F.; Greene, T.; et al. A new equation to estimate glomerular filtration rate. Ann. Intern. Med. 2009, 150, 604-612. [CrossRef]

20. Ahmed, M.I.; Aronow, W.S.; Criqui, M.H.; Aban, I.; Love, T.E.; Eichhorn, E.J.; Ahmed, A. Effects of peripheral arterial disease on outcomes in advanced chronic systolic heart failure: A propensity-matched study. Circ. Heart Fail. 2010, 3, 118-124. [CrossRef]

21. Wei, B.; Qian, C.; Fang, Q.; Wang, Y. The Prognostic Value of Peripheral Artery Disease in Heart Failure: Insights from a Meta-analysis. Heart Lung Circ. 2016, 25, 1195-1202. [CrossRef] [PubMed]

22. Knoops, K.T.; de Groot, L.C.; Kromhout, D.; Perrin, A.E.; Moreiras-Varela, O.; Menotti, A.; van Staveren, W.A. Mediterranean diet, lifestyle factors, and 10-year mortality in elderly European men and women: The HALE project. JAMA 2004, 292, 1433-1439. [CrossRef] [PubMed]

23. Tognon, G.; Lissner, L.; Sæbye, D.; Walker, K.Z.; Heitmann, B.L. The Mediterranean diet in relation to mortality and CVD: A Danish cohort study. Br. J. Nutr. 2014, 111, 151-159. [CrossRef] [PubMed]

24. Tognon, G.; Nilsson, L.M.; Lissner, L.; Johansson, I.; Hallmans, G.; Lindahl, B.; Winkvist, A. The Mediterranean diet score and mortality are inversely associated in adults living in the subarctic region. J. Nutr. 2012, 142, 1547-1553. [CrossRef] [PubMed]

25. Sandesara, P.B.; Hammadah, M.; Samman-Tahhan, A.; Kelli, H.M.; O'Neal, W.T. Peripheral artery disease and risk of adverse outcomes in heart failure with preserved ejection fraction. Clin. Cardiol. 2017, 40, 692-696. [CrossRef]

26. Tektonidis, T.G.; Åkesson, A.; Gigante, B.; Wolk, A.; Larsson, S.C. A Mediterranean diet and risk of myocardial infarction, heart failure and stroke: A population-based cohort study. Atherosclerosis 2015, 243, 93-98. [CrossRef]

27. Fung, T.T.; Rexrode, K.M.; Mantzoros, C.S.; Manson, J.E.; Willett, W.C.; Hu, F.B. Mediterranean diet and incidence of and mortality from coronary heart disease and stroke in women. Circulation 2009, 119, 1093-1100. [CrossRef]

28. Tsivgoulis, G.; Psaltopoulou, T.; Wadley, V.G.; Alexandrov, A.V.; Howard, G.; Unverzagt, F.W.; Moy, C.; Howard, V.J.; Kissela, B.; Judd, S.E. Adherence to a Mediterranean diet and prediction of incident stroke. Stroke 2015, 46, 780-785. [CrossRef]

29. Grosso, G.; Marventano, S.; Yang, J.; Micek, A.; Pajak, A.; Scalfi, L.; Galvano, F.; Kales, S.N. A comprehensive meta-analysis on evidence of Mediterranean diet and cardiovascular disease: Are individual components equal? Crit. Rev. Food Sci. Nutr. 2017, 57, 3218-3232. [CrossRef]

30. Tektonidis, T.G.; Åkesson, A.; Gigante, B.; Wolk, A.; Larsson, S.C. Adherence to a Mediterranean diet is associated with reduced risk of heart failure in men. Eur. J. Heart Fail. 2016, 18, 253-259. [CrossRef]

31. Wirth, J.; di Giuseppe, R.; Boeing, H.; Weikert, C. A Mediterranean-style diet, its components and the risk of heart failure: A prospective population-based study in a non-Mediterranean country. Eur. J. Clin. Nutr. 2016, 70, 1015-1021. [CrossRef] [PubMed]

32. Papadaki, A.; Martínez-González, M.; Alonso-Gómez, A.; Rekondo, J.; Salas-Salvadó, J.; Corella, D.; Ros, E.; Fitó, M.; Estruch, R.; Lapetra, J.; et al. Mediterranean diet and risk of heart failure: Results from the PREDIMED randomized controlled trial. Eur. J. Heart Fail. 2017, 19, 1179-1185. [CrossRef] [PubMed]

33. Dos Reis Padilha, G.; D'almeida, K.S.M.; Ronchi Spillere, S.; Corrêa Souza, G. Dietary Patterns in Secondary Prevention of Heart Failure: A Systematic Review. Nutrients 2018, 10, 828. [CrossRef] [PubMed]

34. Liyanage, T.; Ninomiya, T.; Wang, A.; Neal, B.; Jun, M.; Wong, M.G.; Jardine, M.; Hillis, G.S.; Perkovic, V. Effects of the Mediterranean Diet on Cardiovascular Outcomes-A Systematic Review and Meta-Analysis. PLoS ONE 2016, 11, e0159252. [CrossRef] [PubMed]

35. Miró, Ò.; Estruch, R.; Martín-Sánchez, F.J.; Gil, V.; Jacob, J.; Herrero-Puente, P.; Herrera Mateo, S.; Aguirre, A.; Andueza, J.A.; Llorens, P. Adherence to Mediterranean Diet and All-Cause Mortality After an Episode of Acute Heart Failure: Results of the MEDIT-AHF Study. JACC Heart Fail. 2018, 6, 52-62. [CrossRef]

36. Cooper, H.A.; Exner, D.V.; Domanski, M.J. Light-to-moderate alcohol consumption and prognosis in patients with left ventricular systolic dysfunction. J. Am. Coll. Cardiol. 2000, 35, 1753-1759. [CrossRef]

37. Petrone, A.B.; Gaziano, J.M.; Djoussé, L. Alcohol consumption and risk of death in male physicians with heart failure. Am. J. Cardiol. 2014, 114, 1065-1068. [CrossRef]

38. Sadhu, J.S.; Novak, E.; Mukamal, K.J.; Kizer, J.R.; Psaty, B.M.; Stein, P.K.; Brown, D.L. Association of Alcohol Consumption After Development of Heart Failure With Survival Among Older Adults in the Cardiovascular Health Study. JAMA Netw. Open 2018, 1, e186383. [CrossRef]

39. Larsson, S.C.; Orsini, N. Red meat and processed meat consumption and all-cause mortality: A meta-analysis. Am. J. Epidemiol. 2014, 179, 282-289. [CrossRef]

40. Schwingshackl, L.; Schwedhelm, C.; Hoffmann, G.; Lampousi, A.M.; Knüppel, S.; Iqbal, K.; Bechthold, A.; Schlesinger, S.; Boeing, $\mathrm{H}$. Food groups and risk of all-cause mortality: A systematic review and meta-analysis of prospective studies. Am. J. Clin. Nutr. 2017, 105, 1462-1473. [CrossRef]

41. Zhong, V.W.; Van Horn, L.; Greenland, P.; Carnethon, M.R.; Ning, H.; Wilkins, J.T.; Lloyd-Jones, D.M.; Allen, N.B. Associations of Processed Meat, Unprocessed Red Meat, Poultry, or Fish Intake With Incident Cardiovascular Disease and All-Cause Mortality. JAMA Intern. Med. 2020, 180, 503-512. [CrossRef] [PubMed]

42. Cui, K.; Liu, Y.; Zhu, L.; Mei, X.; Jin, P.; Luo, Y. Association between intake of red and processed meat and the risk of heart failure: A meta-analysis. BMC Public Health 2019, 19, 354. [CrossRef] [PubMed] 
43. Zeraatkar, D.; Han, M.A.; Guyatt, G.H.; Vernooij, R.W.M.; El Dib, R.; Cheung, K.; Milio, K.; Zworth, M.; Bartoszko, J.J.; Valli, C.; et al. Red and Processed Meat Consumption and Risk for All-Cause Mortality and Cardiometabolic Outcomes: A Systematic Review and Meta-analysis of Cohort Studies. Ann. Intern. Med. 2019, 171, 703-710. [CrossRef] [PubMed]

44. Wang, X.; Lin, X.; Ouyang, Y.Y.; Liu, J.; Zhao, G.; Pan, A.; Hu, F.B. Red and processed meat consumption and mortality: Dose-response meta-analysis of prospective cohort studies. Public Health Nutr. 2016, 19, 893-905. [CrossRef] [PubMed]

45. Evangelista, L.S.; Jose, M.M.; Sallam, H.; Serag, H.; Golovko, G.; Khanipov, K.; Hamilton, M.A.; Fonarow, G.C. High-protein vs. standard-protein diets in overweight and obese patients with heart failure and diabetes mellitus: Findings of the Pro-HEART trial. ESC Heart Fail. 2021, 8, 1342-1348. [CrossRef] [PubMed]

46. Lee, C.L.; Liu, W.J.; Wang, J.S. Associations of low-carbohydrate and low-fat intakes with all-cause mortality in subjects with prediabetes with and without insulin resistance. Clin. Nutr. 2021, 40, 3601-3607. [CrossRef] [PubMed]

47. Matre, Å.O.; Van Parys, A.; Olsen, T.; Haugsgjerd, T.R.; Baravelli, C.M.; Nygård, O.; Dierkes, J.; Lysne, V. The Association of Meat Intake With All-Cause Mortality and Acute Myocardial Infarction Is Age-Dependent in Patients With Stable Angina Pectoris. Front. Nutr. 2021, 8, 642612. [CrossRef]

48. Key, T.J.; Appleby, P.N.; Bradbury, K.E.; Sweeting, M.; Wood, A.; Johansson, I.; Kühn, T.; Steur, M.; Weiderpass, E.; Wennberg, M.; et al. Consumption of Meat, Fish, Dairy Products, and Eggs and Risk of Ischemic Heart Disease. Circulation 2019, 139, 2835-2845. [CrossRef]

49. Levine, M.E.; Suarez, J.A.; Brandhorst, S.; Balasubramanian, P.; Cheng, C.W.; Madia, F.; Fontana, L.; Mirisola, M.G.; GuevaraAguirre, J.; Wan, J.; et al. Low protein intake is associated with a major reduction in IGF-1, cancer, and overall mortality in the 65 and younger but not older population. Cell Metab. 2014, 19, 407-417. [CrossRef]

50. Oosterwijk, M.M.; Groothof, D.; Navis, G.; Bakker, S.J.L.; Laverman, G.D. High-Normal Protein Intake Is Not Associated With Faster Renal Function Deterioration in Patients With Type 2 Diabetes: A Prospective Analysis in the DIALECT Cohort. Diabetes Care 2022, 45, 35-41. [CrossRef]

51. The Lancet. Taking sex into account in medicine. Lancet 2011, 378, 1826. [CrossRef]

52. Song, M.; Fung, T.T.; Hu, F.B.; Willett, W.C.; Longo, V.D.; Chan, A.T.; Giovannucci, E.L. Association of Animal and Plant Protein Intake With All-Cause and Cause-Specific Mortality. JAMA Intern. Med. 2016, 176, 1453-1463. [CrossRef] [PubMed] 